\title{
Influência hollywoodiana e o olhar estrangeiro na consolidação da indústria cinematográfica mexicana: um cinema (trans)nacional?
}

\author{
Andréa Helena Puydinger De Fazio ${ }^{1}$
}

\begin{abstract}
Resumo: Os anos de 1930 e 1940 são marcados, no México, por uma intensa produção fílmica, compreendida como resultante de projetos de modernização governamentais. Inseridos no esforço de problematizar essa produção e buscando expor complexidades e interações presentes neste período, propomos, no presente artigo, investigar o fio condutor que conecta a implementação de uma indústria cinematográfica no México e a consolidação dos governos pós-revolucionários, os quais resultam no desenvolvimento de um cinema possuidor de caráter ideológico e esteticamente nacionalista, mas de claras influências estadunidenses no que diz respeito à tecnologia, modelo industrial e estilos de narrativa, bem como de uma simbologia produzida por diferentes expressões artísticas, nacionais e internacionais. Dessa forma, acreditamos que o cinema mexicano no contexto em questão se conforma para além do nacional, consolidando-se por meio de uma rede complexa de interações e diálogos.
\end{abstract}

Palavras-chave: México, cinema transnacional, Era de Ouro.

\section{Hollywood influence and the foreign look in the consolidation of the Mexican film industry: a (trans)national cinema?}

\begin{abstract}
The years of 1930 and 1940 are marked, in Mexico, by an intense film production, understood as a result of governmental modernization projects. In an effort to problematize this production and seek to expose complexities and interactions present in this period, we propose, in this article, to investigate the thread that connects the implementation of a film industry in Mexico and the consolidation of post-revolutionary governments, which Development of an ideologically and aesthetically nationalistic cinema, but of clear American influences with respect to technology, industrial model and narrative styles, as well as a symbology produced by different artistic expressions, national and foreign. Thus, we believe that Mexican cinema in the context in question conforms beyond the national, consolidating itself through a complex network of interactions and dialogues.
\end{abstract}

Keywords: Mexico, transnational cinema, Golden Age.

Recebido em: 31/08/2017

Aprovado em: 18/11/2017

\footnotetext{
${ }^{1}$ Professora de História da América na Universidade Estadual de Montes Claros/MG - UNIMONTES. Mestre e doutoranda em História pela Universidade Estadual Paulista - UNESP/Assis, com pesquisa intitulada A estética de Gabriel Figueroa na busca por um imaginário nacional mexicano: Diálogos entre cinema e pintura, desenvolvida com apoio a Fundação de Amparo à Pesquisa de Minas Gerais FAPEMIG. Email: andreahpf@gmail.com.
}

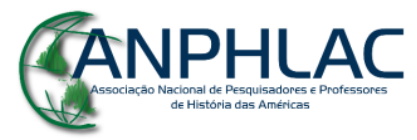

Revista Eletrônica da ANPHLAC, ISSN 1679-1061, №. 23, p. 146-173, Jul./Dez., 2017. http://revista.anphlac.org.br 
O termo Idade ou Era de Ouro é utilizado amplamente, tanto em textos não acadêmicos quanto pela historiografia especializada, para identificar o período em que se deu o desenvolvimento da indústria cinematográfica mexicana, acompanhado de intensa produção fílmica e da construção de uma ampla rede de distribuição e circulação do cinema nacional. Se há discordâncias entre os estudiosos do período, como Emílio Garcia Riera, Jorge Ayala Blanco, Aurélio de los Reyes, Eduardo de la Vega Alfaro, José Carlos Monteiro, Paulo Paranaguá, Tunico Amancio, Ricardo Pérez Montfort, em relação à exata periodização do termo, estando a era dourada de maneira geral situada nas décadas de 1930, 1940 e 1950, a temática e abordagem nacionalista não escapam às menções e análises acerca do período.

Segundo Monteiro (2011), para além da periodização e da definição dos filmes que marcam o início e término da Era, das produções inseridas neste contexto e dos atores, diretores e profissionais diversos que nele atuaram, faz-se necessário, para que se compreenda efetivamente o seu significado para a história do cinema no México, problematizar os processos sociais, políticos e históricos que a possibilitaram, as ideologias nela envolvidas e as influências internas e externas nela presentes - esforço que vem sendo empreendido por estudiosos mexicanos ou mexicanistas a partir das últimas décadas do século XX.

Também inseridos neste esforço, buscaremos, no presente artigo, levantar problematizações sobre a Era de Ouro, investigando o fio condutor que conecta a implementação de uma indústria cinematográfica no México e a consolidação dos governos pós-revolucionários, os quais resultam no desenvolvimento de um cinema possuidor de caráter ideológico e esteticamente nacionalista, mas de claras influências estadunidenses no que diz respeito à tecnologia, modelo industrial e estilos de narrativa.

Ainda, buscaremos inserir na discussão a influência de imagens e representações sobre o México produzidas por artistas estrangeiros - no caso, por Sergei Eisenstein na obra não concluída Que Viva México! -, de forma a apontar como a circulação de imagens de simbologia nacionalista não está presente apenas nas diferentes formas de expressão artística - pintura, fotografia, cinema -, mas também se expande para além das fronteiras nacionais.

Partimos do pressuposto de que a complexidade existente no cinema mexicano da Era de Ouro se faz presente nas controvérsias que marcam esse contexto. Por um

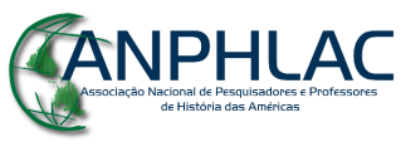

Revista Eletrônica da ANPHLAC, ISSN 1679-1061, №. 23, p. 146-173, Jul./Dez., 2017. http://revista.anphlac.org.br 
lado, o México é um país no qual o nacionalismo estatal pós-revolucionário incentiva o desenvolvimento de um imaginário em torno de sua força política, social e cultural e cujo governo, em diferentes momentos, incentiva a construção de imagens sobre o mexicano, que se enraíza, através das artes, de forma a romper o tempo e o espaço. Por outro lado, o desenvolvimento de sua indústria cinematográfica apresenta-se como consequência direta de um processo mais amplo de industrialização e modernização, tendo a influência direta dos EUA para a consolidação de ambas. Essa influência se dá por meio de investimentos econômicos pautados por interesses políticos, ideológicos e estratégicos, e acaba por gerar, também, uma aproximação de ordem técnica e de estrutura narrativa entre ambos os países.

Dessa forma, acreditamos que, a despeito de sua ideologia nacionalista, o cinema mexicano, no contexto em questão, estrutura-se para além do nacional, sendo marcado por estruturas, padrões e formas estrangeiras - em especial hollywoodianas -, e diretamente influenciado por imagens construídas por artistas não mexicanos, consolidando-se por meio de uma rede complexa de interações e diálogos. Trata-se de uma cinematografia que, desde a produção até a exibição, é marcada pelos processos de globalização - processos estes que, para além dos aspectos econômicos e políticos, também se fazem presentes na cultura. Assim, se por um lado o cinema nacional/nacionalista geralmente se identifica como resultado de características, estilos, identidade de determinado país e uma resistência à dominação estrangeira, por outro lado, a internacionalização de tecnologias, profissionais, imagens, mecanismos de produção, distribuição, exibição e consumo tornam cada vez mais tênue a linha que limita as fronteiras do nacional (EZRA; ROWDEN, 2006; ARROYO; RAMEY; SCHUESSLER, 2011; PÉREZ MELGOSA, 2012; BAMBA, 2013).

Segundo Valdellós e Muñoz (2011), o conceito de cinema transnacional, geralmente utilizado para identificar a colaboração técnica, artística e coprodução internacional, também engloba as proximidades econômicas, políticas, estéticas e temáticas. "A idéia ajuda a interpretar a relação entre o global e o local, o nacional e o inter e transnacional das conexões culturais em relação ao cinema" (VALDELLÓS; MUÑOZ, 2011, p. 4).

Pérez Melgosa (2012) utiliza o conceito "zona de contato" de Mary Louise Pratt para refletir sobre o diálogo cinematográfico entre os Estados Unidos e a América

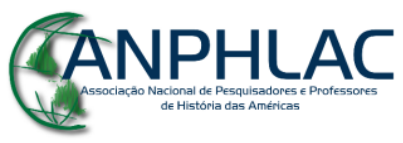

Revista Eletrônica da ANPHLAC, ISSN 1679-1061, №. 23, p. 146-173, Jul./Dez., 2017. http://revista.anphlac.org.br 
Latina. Nestes “[...] espaços onde as culturas se encontram, chocam e se aglomeram, muitas vezes em contextos de relações de poder altamente assimétricas" (PRATT, 1992 apud PÉREZ MELGOSA, 2012, p. 9), há um fluxo constante de talentos, gêneros, técnicas, filmes, modelos culturais e tecnologias - fluxo este que se mostra assimétrico, devido à posição ocupada mundialmente pela indústria cinematográfica hollywoodiana. "Essas trocas constantes transformaram o cinema em um real espaço de zona de contato, choque e troca [...]" (PÉREZ MELGOSA, 2012, p. 9), além de influenciarem nas representações de um país por outro que, muitas vezes, promovem uma homogeneização dos espaços nacionais e a diferenciação dos espaços internacionais, levando a um "complexo jogo de presença e apagamento" (PÉREZ MELGOSA, 2012, p. 9).

No caso mexicano, a ênfase nos termos nacional e nacionalista relaciona-se diretamente ao contexto pós-revolucionário de consolidação do Estado e enraizamento de elementos identitários, no qual a valorização de determinados estilos narrativos resulta de sua aproximação e diálogo com a ideologia nacional. Uma "conveniente ilusão" (ARROYO; RAMEY; SCHUESSLER, 2011, p. 5), o cinema nacional/nacionalista possibilita aos poderes hegemônicos "instituir como politicamente dominante um aspecto particular de uma formação cultural pluralista, e estandartizá-la ou naturaliza-la” (HIGSON, 1989, p. 134 apud ARROYO; RAMEY; SCHUESSLER, 2011, p. 5). No entanto, segundo os mesmos autores, a indústria cinematográfica mexicana, além de ter seu desenvolvimento possibilitado pela relação colaborativa entre EUA e México que evidencia uma estrutura transnacional, também é marcada por um significativo esforço do próprio governo pós-revolucionário em encobrir a dependência internacional. O discurso nacional/nacionalista seria, de acordo com esse viés, construído e utilizado pela política oficial para camuflar a internacionalização das relações político-econômicas mexicanas.

Desenvolveremos o presente artigo em três diferentes momentos. Inicialmente, levantaremos reflexões sobre o significado e as implicações do nacionalismo cultural empreendido pelo Estado no contexto pós-revolucionário. Posteriormente, abordaremos o desenvolvimento da indústria cinematográfica mexicana, traçando paralelos entre os empreendimentos governamentais, os interesses e investimentos estadunidenses e as características hollywoodianas absorvidas pelo cinema mexicano, percebendo-o como

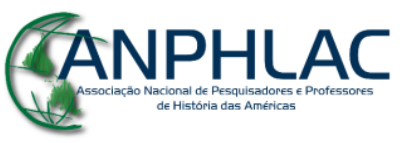

Revista Eletrônica da ANPHLAC, ISSN 1679-1061, №. 23, p. 146-173, Jul./Dez., 2017. http://revista.anphlac.org.br 
um cinema para além da ideologia nacionalista. Em um último momento, buscaremos inserir a idealização, desenvolvimento e representações presentes na obra inconclusa Que Viva México! no rol de imagens tipicamente mexicanas, influenciando fortemente a produção imagética nacional, ao mesmo tempo em que a presença de Eisenstein e sua equipe era vista com desconfiança pelo governo mexicano.

\title{
Revolução Mexicana, imaginário nacional e nacionalismo cultural
}

\begin{abstract}
Os 20 anos que compreenderam a pacificação do território mexicano depois da violência revolucionária - 1920 a 1940 -, foram particularmente ricos em confrontos e polêmicas, definições e discursos, propostas artísticas e culturais, projetos econômicos e políticos. Uma insistente retórica nacionalista permeou a maioria destas propostas. Embora o nacionalismo já fizesse parte da enorme bagagem cultural que o México revolucionário herdou do conflituoso século XIX, um forte impulso introspectivo, com certos ares renovadores, deixou-se sentir no país a partir da instalação da chamada "era dos caudilhos". (PÉREZ MONTFORT, 2007, p. 516)
\end{abstract}

Como esclarecem as palavras de Pérez Montfort (2007), as iniciativas governamentais do contexto pós-revolucionário se inserem em um longo processo de construção e consolidação da identidade e do imaginário nacional mexicano, processo que ocorre desde as lutas pela independência política e permeia toda a construção do Estado mexicano, alcançando grande visibilidade, importância e urgência em determinados períodos-chave para a organização político-institucional do país. A Revolução Mexicana representou, a nosso ver, um destes marcos.

A Revolução, noticiada diariamente em meios de comunicação impressos, amplamente filmada e fotografada, ecoou, segundo Barbosa (2007), no meio artístico mexicano, latino-americano, brasileiro e estadunidense. Internacionalmente, principalmente nas representações construídas pelos Estados Unidos, o México revolucionário foi repetidamente identificado pela barbárie, exotismo, desordem e inferioridade. Segundo Vanderwood e Samponaro (apud MRAZ, 2009, p. 60), "fotografias dos alemães durante a I Guerra Mundial, ou até de espanhóis durante a Guerra Hispano-Americana, estavam longe de ser tão terríveis e degradantes como aquelas dos mexicanos durante a Revolução".

Segundo Mraz (2009), Pérez Montfort (2007, 2015) e Monsiváis (1988), foi em meio a esse emaranhado de representações racistas e estereotipadas que os mexicanos

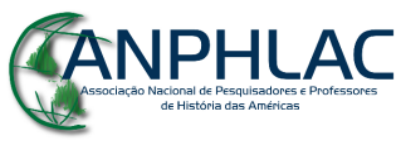

Revista Eletrônica da ANPHLAC, ISSN 1679-1061, №. 23, p. 146-173, Jul./Dez., 2017. http://revista.anphlac.org.br 
passaram a (re)construir sua própria imagem. Monsiváis (1988) vê na Revolução as portas de entrada para o século XX, Revolução que não se reduz ao período de luta armada, mas também inclui os posteriores aparatos de controle governamental e a perspectiva unificadora oficial. As dimensões sociais da Revolução geram, segundo Mraz (2009), a necessidade de reconstrução do país, representando a busca pela mexicanidade, o afastamento de referenciais culturais estrangeiros e a descoberta das raízes nacionais - esforços constantes deste governo pós-revolucionário.

Já no alvorecer da década de 1920, inicia-se a formação do Estado Moderno Mexicano e, na administração de Alvaro Obregón, José Vasconcelos assume o cargo de Secretário de Educação Pública. Vasconcelos, dando início a

[...] uma campanha pela erradicação do analfabetismo, fundou bibliotecas e contratou uma série de artistas para pintarem as paredes de edifícios das repartições públicas, dando origem à Escola Mexicana de Pintura ou Muralismo. (BARBOSA, 2007, p. 19)

Seu programa educacional, expõe Monsiváis (1988), tinha como intenções: desenvolver a educação como atividade evangelizadora, fundando escolas rurais a fim de alfabetizar e despertar uma mínima consciência cultural nos mexicanos do campo, ensinando aos camponeses, além da instrução básica, história e geografia, higiene, artesanato local; a construção de bibliotecas; difusão e promoção das artes, através da fundação do Departamento de Belas Artes, que tinha como função divulgar pedagogicamente a pintura, escultura, música, danças populares; incorporar a minoria indígena através de um sistema escolar integrado, baseado na língua espanhola. Importante notar que todas essas propostas e ações giravam em torno de um ideal específico de nação e unidade nacional, isso pois:

A Unidade Nacional é a terra firme e o salvo-conduto: funde harmoniosamente as classes sociais, as tendências ideológicas, as conquistas antagônicas, os heróis opostos ou contraditórios. [...] A Unidade Nacional é o requisito para o Progresso, a exaltação do sincretismo como garantia do equilíbrio político, cultural e social. Desunidos, somos vítimas propícias do inimigo (o imperialismo, a oligarquia, a subversão, a direita, a esquerda). Congrega-nos o sentimento nacionalista (virtudes insubstituíveis da nossa problemática, perfis próprios, sustentação pelas raízes), o culto aos heróis (a cultura e a história como antologia de personalidades e obras excepcionais, o passado como catálogo ou enumeração orgulhosa, de ruínas pré-hispânicas a Juárez, do muralismo a José Gorostiza). (MONSIVÁIS, 1988, p. 1417)

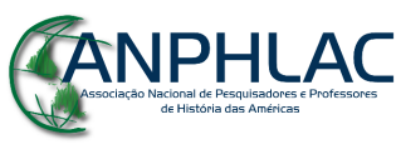

Revista Eletrônica da ANPHLAC, ISSN 1679-1061, №. 23, p. 146-173, Jul./Dez., 2017. http://revista.anphlac.org.br 
Nesse mesmo ano, as celebrações do centenário da Independência já elaboram, por meio da identificação de alguns de seus heróis - Moctezuma, Hernán Cortés, os vice-reis coloniais, Agustín de Iburbide - uma ideia de linearidade e continuidade nacional, inserindo a Revolução no curso da história mexicana, materializando não apenas os grandes homens, mas também o folclore, as artes populares, a mestiçagem étnica e cultural do típico mexicano. O presidente Obregón buscou inserir sua administração no curso da história mexicana, enfatizando a identidade revolucionária de seu governo, as origens indígenas, o caráter mestiço, o descobrimento de uma típica cultura mexicana, materializado com as artes nacionalistas e folclóricas e a música popular (MRAZ, 2009, p. 73). Segundo Capelato (2005, p. 260), “Tais comemorações deram ensejo a reflexões em torno dos problemas nacionais e busca de soluções para eles, o que explica, em parte, as tentativas de revisão das identidades nacionais".

As artes e a cultura deveriam demonstrar a força revolucionária, e a busca por imagens, símbolos, paisagens nacionais se tornam parte inerente ao nacionalismo cultural do governo.

Os debates sobre a Revolução, nacionalismo, história, cultura e raça, giravam em torno do que era, no momento, a temática central: o povo mexicano. "Definir o país e seu povo, explicar suas diversas e próprias manifestações, foi a tarefa que uniu artistas e intelectuais com as maiorias" (PÉREZ MONTFORT, 2007, p. 520). Segundo o mesmo autor, o povo mexicano e a revolução transformaram-se, a partir de seus usos pelos regimes políticos pós-revolucionários, em espécies de entes abstratos. O povo passou a ser identificado, no âmbito político, econômico e cultural, como o protagonista da Revolução e aquele que deveria ser por ela beneficiado. Camponeses, proletários, indígenas, mestiços, classe média, eram integrantes desse povo, o qual, aos olhos das mais diferentes camadas - artistas, intelectuais, elites, políticos - estava inteiramente ligado ao nacionalismo pós-revolucionário.

Os estereótipos surgem nas diferentes representações nacionalistas - as quais, inicialmente, diferiam de acordo com os interesses e intenções de diferentes camadas sócio-políticas. Karen Cordero Reiman (2002) mostra que o fator decisivo para a ênfase dada à "arte popular" foi a associação de ideias com os interesses políticos dos artistas e

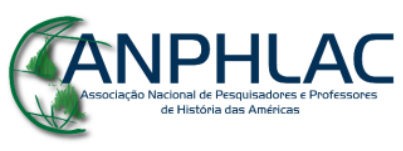

Revista Eletrônica da ANPHLAC, ISSN 1679-1061, №. 23, p. 146-173, Jul./Dez., 2017. http://revista.anphlac.org.br 
intelectuais mexicanos, a qual se deu mais especificamente no governo de Álvaro Obregón. A partir desse momento, a base do programa político nacionalista foi a

[...] homogeneização da população rural e a vinculação de sua identidade simbólica com a do governo federal. É nesse contexto que a ideia romântica de que a cultura popular incorpora uma essência do nacional e se relaciona com os valores de autenticidade, pureza, espontaneidade, primitivismo e comunidade, foi retomada pelos intelectuais do período como um veículo simbólico e como uma área de intervenção e manipulação real de economias locais e formas de vida, assim como sua relação com estruturas nacionais. (CORDERO REIMAN, 2002, p. 70)

As artes visuais marcaram o período em questão na condição de formadoras e difusoras de um imaginário sobre o México, institucionalizando símbolos-chave para a referência a esta cultura: as pirâmides astecas, as caveiras de José Guadalupe Posada, os murais de José Clemente Orozco, Diego Rivera e David Álfaro Siqueiros, os vulcões, o indígena pré-hispânico e sua cultura. As imagens e sons técnicos, segundo John Mraz (2009), ainda que não se sobreponham à fundamental importância das pinturas e litografias no que diz respeito à exploração da questão identitária, mostram-se mais abrangentes e informativos. Pérez Montfort (2007) também acredita que o crescimento e difusão de estereótipos nacionais se deveram muito aos meios massivos de comunicação como teatro, rádio e cinema nos anos trinta e quarenta. $\mathrm{O}$ autor observa que:

\begin{abstract}
A partir de uma visão conservadora - a do camponês e do fazendeiro combinada com os interesses econômicos dos empresários dos novos meios massivos de comunicação, criou-se uma imagem do mexicano que se impôs tanto no mercado interno quanto no exterior [...]. (PÉREZ MONTFORT, 2007, p. 524)
\end{abstract}

Podemos afirmar, então, que a ideia de nacionalismo cultural se legitima e difunde, de fato, nos meios artístico e intelectual. A Escola Mexicana de Pintura pode ser vista como o principal meio através do qual Vasconcelos buscou propagar a Revolução Mexicana e transmitir sua teoria da Raça Cósmica. O muralismo passa a ser visto como, nas palavras de Octavio Paz (apud MONSIVÁIS, 1988, p. 1422), “um descobrimento do presente e do passado do México, algo que o tremor revolucionário havia colocado à vista".

Também, a abertura do Museu Nacional de Arte Popular e a inauguração do Palácio de Bellas Artes, no ano de 1934, mostram essa direta associação entre arte 
popular, pintores profissionais e a política nacionalista. $\mathrm{O}$ resgate de referências populares pode ser visto, ainda, no trabalho do artista Leopoldo Méndez, fotógrafos como Edward Weston, Tina Modotti e Manuel Álvarez Bravo - os quais estabelecem diálogos entre a realidade cotidiana e o estilizado. A pintura também ocupa espaço essencial nesse processo, passando a fazer parte de um contexto que vê o artista como um trabalhador a serviço da sociedade. Interessante notar, conforme expõe Cordero Reiman (2002), que, através destes canais produtores de imagens, o repertório de fontes visuais para a cultura artística nacional foi ampliado, mesmo que o resgate dessas fontes visuais tenha se dado originalmente devido aos interesses político-ideológicos.

Projetos governamentais desenvolvidos durante os mandatos de Plutarco Elías Calles, Lázaro Cárdenas, Manuel Ávila Camacho e Miguel Alemán deram continuidade, com mais ou menos intensidade, aos ideais estabelecidos inicialmente por Vasconcelos. O contraditório, conforme exposto por Pérez Montfort (2005), é que, caracterizar o povo, estudá-lo e identificar suas manifestações foram tarefas que uniram artistas e intelectuais, fazendo com que a busca pelo popular, pelo mexicano, pelo nacional, fossem empreendimentos cada vez mais afastados do próprio povo.

Elementos naturais - como a raça, a paisagem, a geografia - e culturais, as tradições e costumes, remetiam a uma história nacional, um passado e um futuro comuns (CUEVA, 2005). A cultura nacional mexicana passa a ser transmitida através de um discurso oficial, o qual resulta da criação e consolidação de mitos acerca de sua identidade. Para Roger Bartra (1996) é o nacionalismo que estabelece a relação entre a cultura e o Estado - "um sedimento cultural que é socialmente peneirado através do tempo de muitas maneiras [...] e através de práticas cotidianas e de projetos oficiais" (BARTRA, 1996, p. 29), tornando-o tanto um fenômeno social quanto cultural ou político. Assim, a cultura oficial pós-revolucionária seria a institucionalização de uma ideologia que, por sua vez, explica e direciona o processo de formação de uma identidade nacional mítica.

\section{O desenvolvimento da indústria cinematográfica mexicana}

A febre do folclore paralizou o cinema mexicano, atou-o a uma inexorável monotonia insistentemente destacada pelos críticos e tão tenaz, entretanto, que nada pode deslocá-lo [...]. O charro, a poblana chinesa, a canção chorosa,

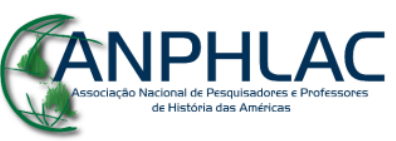

Revista Eletrônica da ANPHLAC, ISSN 1679-1061, №. 23, p. 146-173, Jul./Dez., 2017.

http://revista.anphlac.org.br 
ou fanfarrona, tudo isso são coisas que se repetem incessante, implacavelmente. Dir-se-ia que o México é, sobretudo, cantores, sombreiros, anchos e violões [...]. E é um erro, um grande erro. O México não se caracteriza por isso, ainda que, certamente, tais tipos predominam numericamente no país, com traços muito distintos ao que nosso cinema lhes atribui [...]. (MALLEN, 1938 apud PÉREZ MONTFORT, 2007, p. 525) ${ }^{2}$

A influência do nacionalismo cultural no cinema empreendido pelo Estado mexicano, bem como da construção do povo mexicano, do típico, do tradicional derivadas daqueles empreendimentos, ficam claras nas palavras do crítico Rubén Mallen. Podemos perceber que as várias críticas dirigidas à pintura muralista, principalmente no que diz respeito à controvérsia de ser uma arte supostamente revolucionária e trabalhar em prol de projetos estatais homogeneizantes, estenderam-se ao cinema - o qual é entendido por nós como um elemento de continuidade no desenvolvimento do nacionalismo cultural, fio condutor das ações políticas na primeira metade do século XX.

Ainda que, até o alvorecer dos anos de 1930, o cinema ainda não ocupara o espaço de meio de comunicação massivo para fins educativos e de propaganda governamental, desde seus primórdios, as produções fílmicas no México apresentam caráter político. Já na década de 1910, por exemplo, Felipe de Jesús Haro realiza El grito de Dolores, filme sobre as festas da Independência e documentaristas como Julio Lamadrid, Enrique Rosas, Manuel Becerril, Jesús Abitia e os irmãos Alva registram desfiles militares, eventos de natureza oficial e a Revolução Mexicana. Até os anos de 1920, empresas como Azteca Films, Cuauhtémoc Films, Bandera Films, Film Colonial, Productora Quetzal fazem com que a indústria fílmica mexicana se mantenha, com uma produção de aproximadamente 10 filmes por ano (SCHUMANN, 1987).

Já durante a década de 1920, entre o final da Revolução Mexicana e o surgimento do cinema sonoro (1930), devido à abertura do país para produtos estrangeiros e a instalação de distribuidoras de cinema estadunidense no México, o cinema nacional praticamente desapareceu. Nesses anos, Hollywood passou a ser um espaço de formação e início de carreira para diversos atores mexicanos, como Dolores del Rio, Ramón Novarro, Lupe Véleze Rosita Moreno (TORRES; ESTREMERA, 1973).

\footnotetext{
${ }^{2} \mathrm{O}$ artigo citado foi escrito por Rúben Salazar Mallen, intitulado Más calidad y menos cantidad exige el público. Publicado pelo periódico Cine México em outubro de 1938.
} 
Os mexicanos tinham motivos para entrar em recesso. O mercado fora invadido irreversivelmente pelos Estados Unidos. [...] Nos anos de 1920, as imagens hollywoodianas empalideceram as raras imagens mexicanas na tela. O eclipse imagético ocorreu justamente quando o México estava consolidando uma tradição de boa fotografia (Manuel Alvarez Bravo, Romualdo Garcia, Agustín Victor Casasola, Hugo Brehme e os irmãos Alva) e aprimorava seu artesanato na técnica de filmar. Em 1920, 55,7\% das estreias eram norte-americanas; em 1927 e 1928 essa cifra subiu para mais de $90 \%$. A exibição se recuperou muito rapidamente graças à produção estrangeira, mas a produção nacional ficou à míngua. (MONTEIRO, 2011, p. 99)

A década de 1930, por sua vez, transforma radicalmente o cenário cinematográfico mexicano, nos mais variados aspectos - produção, distribuição, reconhecimento e investimento governamental e estrangeiro, circulação de profissionais e tecnologia, sistema de estúdios e presença de grandes atores. A consolidação de uma indústria de cinema no país resulta da união de diferentes fatores, específicos do México ou em diálogo com processos vividos por países como Brasil e Argentina. Em 1934, o presidente Lázaro Cárdenas inicia no México um conjunto de reformas sociais e econômicas, atuando na reforma agrária, elaboração de legislação trabalhista, nacionalização da indústria petrolífera, campanhas de alfabetização e criação de uma indústria nacional. Este último elemento também faz parte da realidade dos países citados, levando ao desenvolvimento de indústrias cinematográficas nacionais e fazendo com que os três países se tornassem responsáveis por $89 \%$ dos filmes realizados na América Latina até o ano 2000, e se destacassem em uma região na qual a maior parte dos países apresentava uma produção ocasional, e, principalmente, apenas distribui e exibe filmes estrangeiros (ALBANO, 2009).

Segundo o mesmo autor, desde a formação dos Estados nacionais latinoamericanos, processos datados do século XIX, a modernização capitalista se espelha em padrões estadunidenses. O período entreguerras, acompanhado de redução drástica da produção cinematográfica europeia e a consequente redução de distribuição na América Latina, também impactaram na mudança de referencial latino-americano, principalmente nos aspectos culturais, pois espaços até então ocupados pela Europa passaram gradualmente a ser substituídos pelo modelo cultural estadunidense. Dessa forma, é possível afirmar que, no início do desenvolvimento cinematográfico nacional na primeira metade do século XX, México, Brasil e Argentina adotaram dinâmicas e

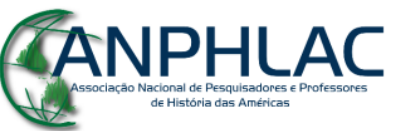

Revista Eletrônica da ANPHLAC, ISSN 1679-1061, №. 23, p. 146-173, Jul./Dez., 2017. http://revista.anphlac.org.br 
elementos presentes na indústria hollywoodiana - star system, grandes estúdios e produtoras, o cinema de gênero (ALBANO, 2009).

Nesse mesmo contexto, o interesse estadunidense na região ao sul do Rio Grande cresce significativamente - período conhecido como Política de Boa Vizinhança - bem como sua participação no desenvolvimento da indústria cinematográfica latinoamericana, aumento da distribuição fílmica na região, aplicação de recursos financeiros e tecnológicos nas cinematografias nacionais. Tamanha é a influência do cinema hollywoodiano na América Latina que, a despeito da produção nacional crescente,

Entre 1930 e 1939, no México, estreiam-se 2.388 filmes norte-americanos (em inglês, 76 por cento do total), 199 filmes mexicanos (6,9 por cento), 91 filmes norte-americanos em castelhano (2,9 por cento), 31 espanhóis (um por cento), 19 argentinos (0,6 por cento). Entre 1940 e 1949, a participação é de 2.864 filmes norte-americanos (em inglês, 69,2 por cento), 629 filmes mexicanos (15,1 por cento), 222 filmes argentinos (5,4 por cento), 58 espanhóis (1,44 por cento), e 3 filmes norte-americanos em espanhol. (ALBANO, 2009, p. 6)

O desenvolvimento das cinematografias nacionais também se deve à chegada do cinema sonoro, possibilitando que especificidades culturais fossem reveladas pela música, canções e folclore locais. A chanchada, o filme tango e o melodrama ranchero foram os gêneros que se destacaram nos primórdios de uma indústria fílmica nacional, articulando a presença do som à construção de um imaginário de Nação e representações identitárias (CASTRO, 2004).

O melodrama ranchero, ou comédia ranchera, é definido por Schumann (1987, p. 222) como uma "espécie de peça popular com abundantes números musicais e com uma agitada história de ciúmes que tem por cenário um rancho do campo mexicano, no qual parece ter concentrado toda a riqueza folclórica do país". Precursor deste gênero, diretamente derivado do contexto de sonorização do cinema, o filme Allá en el Rancho Grande, por exemplo (1936, Dir.: Fernando de Fuentes) carrega a complexidade das produções do período. Isso, pois, "basicamente musical, foi realizada [...] com o objetivo de apoiar diversos interesses midiáticos transnacionais dos investidores financeiros no cinema". (HIGGINS, 2008, p. 125)

O êxito de Alla en el Rancho Grande [...] tanto no México como na América Latina, e inclusive na Espanha e no Festival de Veneza, determina uma nova

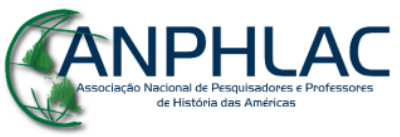

Revista Eletrônica da ANPHLAC, ISSN 1679-1061, №. 23, p. 146-173, Jul./Dez., 2017. http://revista.anphlac.org.br 
etapa no processo de industrialização e consolida o gênero baseado quase exclusivamente nas canções populares. Assim, o mercado hispânico converte-se numa realidade que dá uma nova abertura à capacidade industrial mexicana. Consolidam-se os gêneros e o sistema de estrelas. A produção cresce e, obviamente, padroniza-se, mas este fato está relacionado com as necessidades econômicas. [...] Assim, as necessidades econômicas recorrem às fórmulas de comunicação comprovadas [comédias rancheiras $e \quad o$ melodrama], sem nenhum tipo de originalidade, que respeitam as expectativas do público e garantem a entrada de divisas. (OROZ, 1992, p. 104. Grifo nosso)

Torres e Estremera (1973) e Schumann (1987) esclarecem que, diante do surgimento do cinema sonoro, tanto a predileção do público latino-americano em ouvir sua própria língua, quanto as altas taxas de analfabetismo nesses países (o que diminuía drasticamente o público dos filmes dublados), levaram produtoras estadunidenses a investir na duplicação de versões fílmicas - as quais teriam uma versão falada em espanhol, com atores provenientes dos países latino-americanos. Ainda que essas produções não tenham sido bem sucedidas, reduzindo drasticamente até ser finalizada em 1940, possibilita-nos notar como os espaços nacionais eram interessantes ao empreendimento industrial e fílmico estadunidense.

Seguindo essa linha, podemos notar que uma das estratégias comerciais hollywoodianas diante do cinema mexicano foi atuar na distribuição de filmes deste país - como forma, inclusive, de neutralizar a crescente expressão das produções argentinas na América do Sul -, bem como contratar atores nacionais para atuarem em produções estadunidenses (CASTRO, 2004; HIGGINS, 2008). A Segunda Guerra Mundial e a consequente redução da produção hollywoodiana fizeram com que o México adquirisse uma importância estratégica e recebesse significativos investimentos (TORRES, ESTREMERA, 1973).

Os Estados Unidos viam no México um aliado contra a Alemanha fascista de Hitler e necessitavam das matérias-primas que possuía o país vizinho, de modo que se mostraram generosos não somente com investimentos em diversos setores industriais, mas também contribuíram para o desenvolvimento da indústria cinematográfica com laboratórios de processamento e modernos métodos de distribuição. Os consórcios não viam maior perigo nos filmes mexicanos, mas, no entanto, temiam o cinema do tango argentino como um sério competidor no mercado latino-americano. [...] Adicionalmente, os Estados Unidos dificultaram com medidas políticas a produção cinematográfica de uma Argentina que não ocultava certas simpatias pelo regime de Hitler. Os norte-americanos bloquearam as vendas de filme virgem, para evitar que com esse material se fizesse propaganda fascista no Cone Sul. Desse modo, conseguiram os objetivos: a neutralização

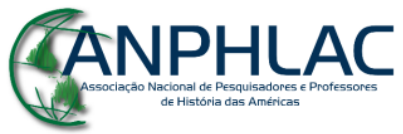

Revista Eletrônica da ANPHLAC, ISSN 1679-1061, №. 23, p. 146-173, Jul./Dez., 2017. http://revista.anphlac.org.br 
de um perigoso competidor (mediante o boicote e a criação de outro competidor) e a inclusão deste no próprio sistema cinematográfico mediante a dependência técnica e econômica. (SCHUMANN, 1987, p. 224)

As palavras de Oroz (1992) e Schuman (1987) citadas acima levantam uma importante discussão no que tange o cinema nacional latino-americano e, mais especificamente, mexicano: a relação entre os gêneros predominantes, o viés estético e os interesses comerciais, políticos e ideológicos estadunidenses. Segundo Bragança (2011, p. 169), os filmes de gênero, resultantes das condições de produção e das dinâmicas capitalistas que os envolvem,

[...] têm o poder de reinventar espaços por meio de cenários-metáforas que repercutem o universo valorativo de uma determinada sociedade. Tais espaços são recorrentemente (re)criados na tela, formando parte do imaginário de uma sociedade [...]. (BRAGANÇA, 2011, p. 169)

Nas telas de cinema, torna-se possível, então, representar símbolos sociais e dotá-los de significados culturais, ou reiterar significados já existentes. Conforme esclarece Silvia Oroz (1992, p. 31), “Todo gênero é um sistema coerente de sinais, convencionalmente estabelecidos e aceitos, que funciona como um estereótipo cultural com dinâmica própria, num determinado contexto histórico".

Notamos, dessa forma, que existe intenso diálogo entre o melodrama ranchero mexicano e os padrões morais da sociedade, sendo características destas produções a narrativa linear de simples compreensão e mensagem única, apresentando modelos e práticas sociais vistas como corretas. "Ou seja: os convencionalismos sociais influenciaram a construção de uma forma narrativa de aceitação popular. Desta maneira, define-se a relação gosto popular/moral social” (OROZ, 1992, p. 30).

As "fórmulas de comunicação comprovadas", acima citadas (OROZ, 1992, p. 104), tão caras aos padrões hollywoodianos e das quais depende o financiamento estrangeiro, também dialogam diretamente com os projetos governamentais das décadas de 1930 e 1940, bem como com as transformações econômicas e sociais deste contexto.

Durante o governo de Lázaro Cárdenas (1934-1940) [...] consolidava-se um novo tipo de classe média, pretensamente moderna e urbana, que começava a impor seus gostos ambíguos e complexos, mas com forte herança rural. Além de heterogênea, é uma classe ferozmente individualista, favorável à penetração do capital estrangeiro, comodamente instalada na concorrência e

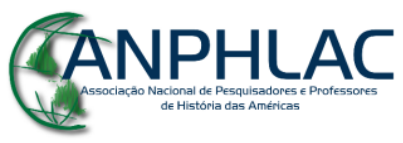

Revista Eletrônica da ANPHLAC, ISSN 1679-1061, №. 23, p. 146-173, Jul./Dez., 2017. http://revista.anphlac.org.br 
no desejo de ascensão social. Esta classe média, católica, monogâmica e nuclear, encerrava-se no lar como refúgio absoluto da preservação da propriedade privada. Ameaçada pelo projeto cardenista, contemplada no subsequente projeto desenvolvimentista de Ávila Camacho (1940-1946), a família dos melodramas familiares mexicanos da década de 1940 vive num mundo à parte, com seu tempo exclusivo, à margem do processo histórico. A separação entre o mundo da rua e da casa é radicalmente postulada, e indispensável para que a família permaneça como um projeto eficiente, que pareça preceder à própria história como algo eterno e intransigentemente incontestável. (BRAGANÇA, 2011, p. 174)

Escobar (2011) acredita que não apenas na tecnologia e estrutura hollywoodiana se inspiram os cinemas nacionais, mas também no seu modelo de narrativa. São características da narrativa clássica hollywoodiana, segundo Xavier (2003, 2005), a presença de personagens psicológica e ideologicamente definidas; a ação destes girando em torno da resolução de conflitos ou desequilíbrios causados por elementos externos; a utilização da trilha sonora e dos recursos de montagem de forma a privilegiar a continuidade no tempo e no espaço, clareza narrativa e moral, de forma que a mensagem central fique clara e seja compreendida amplamente, entre outros elementos usados para a transição no tempo e no espaço, apresentação de personagens e locais ainda desconhecidos pelo espectador, a retomada do equilíbrio interno na parte final da narrativa, etc.

Segundo Escobar (2011), no cinema da América Latina, mais especificamente na Era de Oro do cinema mexicano, a influência hollywoodiana é clara, em especial nos aspectos relativos à linguagem cinematográfica, técnicas narrativas e cultura do star system. No entanto, mais do que a assimilação de convenções tradicionais, o cinema da Era de Ouro se apropria de um gênero diretamente associado à narrativa clássica apresentada: o melodrama. Este, para Escobar, atua no imaginário social, sendo uma história de amor ou um personagem principal o responsável por mediar conflitos existentes em determinada comunidade.

A nosso juízo, o relevante dos filmes da Época de Ouro não é somente que reproduzam uma técnica de montagem ou alguns usos de câmera. O interessante é que se constituem em um espaço discursivo no qual se articulam e aglutinam discursos, práticas e saberes que, graças a um acontecimento discursivo (o cinema melodramático e suas formas), passam a um estado de coerência e unidade, configurando uma cinematografia orgânica que participa ativamente na consolidação da hegemonia. Por exemplo, no filme Allá en el Rancho Grande, as relações de poder e as diferenças sociais que se dão no interior da fazenda somente importam na

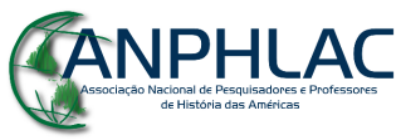

Revista Eletrônica da ANPHLAC, ISSN 1679-1061, №. 23, p. 146-173, Jul./Dez., 2017. http://revista.anphlac.org.br 
medida em que justificam o núcleo do conflito, que é a dificuldade para que se concretize o romance entre o caporal e a mulher-cinderela. Assim, a injustiça da ordem social se volta a ordem natural que o herói do melodrama não somente não pretende subverter, mas também é o que se recebe ao recorrer à ordem estabelecida para solucionar sua situação. Deste modo, ao naturalizar a ordem social, por um lado, e a deslegitimá-la, por outro, ou seja, ao situá-la como uma sorte de telão de fundo, faz-se possível que a trama transcorra para o encontro amoroso. Uma situação similar, podemos apreciar em Enamorada, na qual um duro general revolucionário toma o poder em um pequeno povoado mexicano, mas toda a sua convicção revolucionária passa para o segundo plano ao apaixonar-se por Beatriz, a filha de um dos homens mais ricos do povoado. A Revolução já pouco importa, pois o relevante no filme é o amor. Assim, o fato de que o filme se situe historicamente na época da Revolução Mexicana é intranscendente para o argumento, já que eventualmente poderia ter-se situado na Colônia, na Independência ou em qualquer época histórica, por que o relevante para o filme é a relação amorosa entre dois seres em aparências díspares. (ESCOBAR, 2011, p. 1920)

Percebemos, até o presente momento, que a indústria cinematográfica latinoamericana se constrói mediante significativos investimentos financeiros estadunidenses, bem como interesses político-ideológicos do mesmo país, seus padrões industriais e narrativos. A tecnologia representa um fator essencial nesta equação, pois no que diz respeito à tecnologia necessária para os primeiros passos do cinema mexicano, havia também grande dependência em relação aos EUA: aparelhos Mitchel, Houvell foram comprados neste país, e o material fotográfico Kodak foi comprado na American Photo Suply Company. A tecnologia disponível no México avançou significativamente após a construção dos Estúdios CLASA (Cinematografia Latino-americana S.A.), que também atuavam na produção fílmica, e possuíam equipamentos semelhantes aos que Hollywood possuía: "câmeras Mitchel, equipamento de regravação (ou sonorização sincrônica), máquina de revelar baseada na curva 'gamma', equipamento de projeção de fundo (back-projection) e impressora ótica" (RIERA apud OROZ, 1992, p. 115). Também, a mão de obra especializada era composta, em grande parte, por profissionais formados no exterior, principalmente nos EUA, tais como técnicos, fotógrafos, montadores, cenógrafos, entre outros.

Percebemos que é complexa a relação entre as indústrias de cinema nacionais e os Estados Unidos. Por um lado, no México, a estabilização do Estado pósrevolucionário e a legitimação do governo estão diretamente associados aos processos de modernização e industrialização do país e à consequente necessidade de legitimação do Estado e construção de uma unidade nacional embasada na cultura e identidade. Por

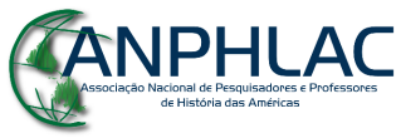

Revista Eletrônica da ANPHLAC, ISSN 1679-1061, №. 23, p. 146-173, Jul./Dez., 2017. http://revista.anphlac.org.br 
outro, a indústria cultural, desnacionalizada por essência, atuou na padronização da nacionalidade em países latino-americanos, "que aclimataram a tecnologia transnacional a suas necessidades de arranjos internos em torno dos sinais de reconhecimento mútuo" (ALBANO, 2009, p. 8).

Se a maioridade do cinema mexicano se deve a uma união de fatores, muitos dos quais já abordados, os empreendimentos governamentais em torno do nacionalismo cultural e a busca pela legitimação política e institucional pós-revolucionária também atuam neste conjunto. Sabemos que a estabilização política do governo de Lázaro Cárdenas representou, entre outras ações, investimentos em políticas reformistas e em políticas culturais - que envolviam o incentivo à produção cinematográfica. Mais tarde, durante o governo de Manuel Ávila Camacho (1940-1946), a produção cinematográfica seguiu apoiada pelo Estado e, conforme já apontado, significativamente impulsionada pela entrada dos Estados Unidos na Segunda Guerra Mundial.

No ano de 1934, foi criada a UTECM, União dos Trabalhadores dos Estúdios Cinematográficos Mexicanos, primeiro sindicato cinematográfico no México. O desenvolvimento desta União derivou diretamente dos empreendimentos modernizadores cardenistas, impulsionando a industrialização e, consequentemente, a sindicalização (OROZ, 1992). Com a ampliação da presença do Estado na indústria cinematográfica, o cinema, por um lado, passou a ter maior importância política, econômica e social, além de financiamento do Banco Nacional Cinematográfico, mas, por outro lado, passou a ser afetado pelos diferentes projetos político-governamentais, pela necessidade de entrar em compasso com os interesses governamentais (ESCOBAR, 2011).

Os empreendimentos governamentais a partir da década de 1930 patrocinavam o estreitamento de relações sociais no México, beneficiando-se desta suposta união e, para que ela fosse legitimada, criando um imaginário nacional que possibilitava governar o amplo leque que constituía o povo mexicano. Os meios de comunicação de massa, bem como as artes, visavam unir temáticas populares, nacionalismo e diversão. Diante das diversas iniciativas de "popularizar y nacionalizar" a cultura mexicana, tanto o povo quanto a própria revolução transformaram-se em "estereótipos culturais que surgiam cada vez que os regimes pós-revolucionários tomavam a palavra" (PÉREZ MONTFORT, 2007, p. 523).

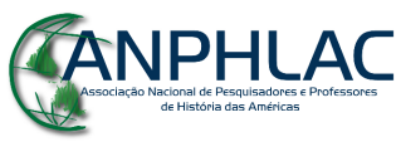

Revista Eletrônica da ANPHLAC, ISSN 1679-1061, №. 23, p. 146-173, Jul./Dez., 2017. http://revista.anphlac.org.br 
Ainda segundo o mesmo autor, paralelamente ao nacionalismo cultural, associado aos elementos populares e revolucionários mexicanos, desenvolveu-se uma visão nacionalista mais elitista, vinculada a padrões e costumes tradicionais, cristãos e familiares. Enquanto o indigenismo associava a mexicanidade e a essência do povo mexicano ao passado indígena, às tradições ancestrais e aos herdeiros destas (os indígenas), o hispanismo acreditava que a religião católica e a língua espanhola teriam moldado o mexicano, passando a ser vistas como provas de que o México se construíra a partir das raízes hispânicas. E a conquista representava, para esta corrente, um duro, porém necessário acontecimento, que fez com que a nação mexicana entrasse no ‘caminho civilizatório'. Visões distintas do que é ser mexicano foram, pouco a pouco, interagindo e, nos anos quarenta, fundiram-se - estando o cinema nacionalista melodramático inserido na representação de uma sociedade de bases tradicionais.

\footnotetext{
O nacional e o popular estão fixados por um conjunto de signos que têm sua ancoragem em uma série de campos simbólicos: o dos espaços sociais (a hacienda, a cantina, a aldeia, a igreja), o das práticas culturais (as corridas de cavalos, as brigas de galo, as serenatas, os matrimônios, etc.), o dos sistemas simbólicos (a arte, a religião, a língua) e o dos personagens (o caporal, o bêbado, o hacendado, o charro, a dama de sociedade, o peão, as soldaderas, o revolucionário, o sacerdote, etc.). Cada um destes campos vem a configurar uma visão particular que necessariamente exclui outras práticas culturais e outros espaços sociais. (ESCOBAR, 2011, p. 24)
}

Na cultura popular e visual, da década de 1920 até o final de 1940, dando continuidade ao pensamento e às artes do século XIX, o indígena foi resgatado e transformado em elemento definidor da mexicanidade, bem como sua linguagem, vestimentas e traços comportamentais, fortemente difundidos no teatro, música popular, pintura e no cinema. Nota-se que este cinema recorria às raízes pré-hispânicas para revelá-lo como base social mexicana, para se diferenciar em temáticas e estética, das produções estrangeiras e até mesmo para nomear seus estúdios e empresas produtoras: Aztlán Films, Popocatépetl Films e Quetzal Films. Paradoxalmente,

Ser índio contemporâneo equivalia mais a ser um personagem à parte, vítima de um passado distante, e, quando muito, simples pretexto para impulsionar campanhas políticas que, em última análise, convertiam-se em demagogia. [...] Assim, ainda que se reconhecesse sua participação na formação do mexicano, o indígena era uma dimensão distante, à parte. (PÉREZ MONTFORT, 2007, p. 538)

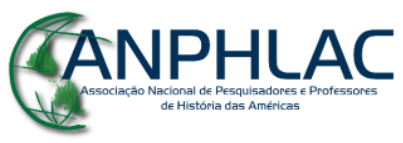

Revista Eletrônica da ANPHLAC, ISSN 1679-1061, №. 23, p. 146-173, Jul./Dez., 2017. http://revista.anphlac.org.br 
O autor citado entende que o cinema mexicano deste período busca construir o imaginário nacional através de uma construção estereotípica que valoriza uma sociedade, geografia, hábitos e costumes imaginados e não se ocupa em retratar a devastação gerada pela modernidade político-econômica. Assim, acredita que o cinema tenha ascendido em meio a um suposto nacionalismo, que se aspirava popular, mas representava, na verdade, ideias e manifestações de uma elite, que estabeleceu categorias rígidas para caracterizar uma múltipla e diversa sociedade e, repetidamente, difundiu-a nos meios de comunicação de massa.

Exemplos claros destes estereótipos nacionais formam as figuras
emblemáticas, primeiro do "el chinaco" e depois o "el charro", a "china
poblana", "el indito", "el fifi" ou "los rotos", "el revolucionário", "la
soldadera", "el peladito", etc. Embora igualmente "mexicanos", também se
formaram outros estereótipos como "la tehuana" do istmo oaxaquenho, "el
jarocho" da costa veracruzana, "el huasteco" da região nordeste do país, "el
norteño" correspondente a todo o território entre a fronteira dos Estados
Unidos e os limites setentrionais da Mesoamérica ou "el boschito" da
península yucateca, cada um representando os "típicos" habitantes daquelas
zonas específicas da república que os identificaram como locais ou próprios
de tal ou qual região. (PÉREZ MONTFORT, 2015, p. 20, grifo nosso, aspas
do autor)

Produto de consumo e exportação, poético e retórico, o México imaginado por meio de imagens de consenso, da roupagem exótica, é considerado por Albano (2009, p. 10) " [...] a apresentação de um mundo harmônico e almejado pelos liberais que pouco a pouco ganhavam influência nas filas do estado mexicano pós-revolucionário". Trata-se de um cinema derivado de processos de modernização estatal, político e social, que se legitima e enraíza através do uso de referenciais, modelos e padrões morais tradicionais, do gênero melodramático, da estrutura familiar, da simbologia cristã.

As estreitas relações entre México e Estados Unidos fazem com que, mesmo buscando o desenvolvimento de uma produção nacional de ideologia nacionalista, o cinema mexicano absorva modelos e padrões hollywoodianos. Produtos característicos do American way of life e palavras em língua inglesa se faziam cada vez mais presentes nos meios de comunicação mexicanos, visuais e impressos, além de valores sociais e morais estadunidenses. Este país, apoiando-se nos discursos de segurança continental,

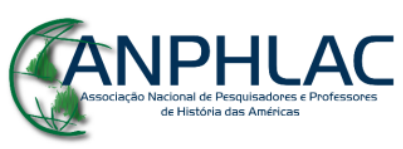

Revista Eletrônica da ANPHLAC, ISSN 1679-1061, №. 23, p. 146-173, Jul./Dez., 2017. http://revista.anphlac.org.br 
visava intensificar a aproximação política, econômica e cultural com países-chave da América Latina.

\begin{abstract}
As abordagens que aqui se desenvolvem partem da base de que o colonialismo territorial e nacionalista da modernidade deu início a um neocolonialismo pós-moderno e desterritorializado. É possível sustentar que os sistemas simbólicos (arte, religião, língua) se convertem em um meio eficaz para conseguir amassar um sistema de dominação que se cristaliza na produção simbólica. Assim se produz (conscientemente ou às cegas) um sistema de dominação que vai mais além e é tão mais efetivo que os tanques, os mísseis e os soldados, posto que as palavras e as imagens atuam sobre a imaginação dos dominadores e os dominados. Como resultado, gera-se uma visão consolidada que afirma não somente o direito de uns sobre outros a dominar, mas também sua obrigação de fazê-lo. (ESCOBAR, 2011, p. 11)
\end{abstract}

\title{
Que Viva México! de Eisenstein e a circulação de imagens nacionais mexicanas
}

Conforme afirmamos acima, faz parte do complexo processo de industrialização e da formação do cinema latino-americano a presença do elemento estrangeiro, não apenas por meio de modelos, padrões e investimentos, mas também na construção e circulação de imagens nacionais - imagens que, mesmo empreendidas por artistas estrangeiros, atuam na formação e promoção de uma iconografia nacional de ideologia nacionalista. As imagens produzidas por estrangeiros podem ser "estranhamente patrióticas" (ALBANO, 2009, p. 8), e como exemplo deste paradoxo podemos citar as representações do México e do mexicano construídas pelo cineasta soviético Sergei Eisenstein - as quais fizeram com que o diretor fosse considerado pioneiro da imagem mexicana na cinematografia ou, pelo menos, responsável por tornar internacional esta imagem (PÉREZ MONTFORT, 2007).

Acreditamos que, mesmo não inserido nos empreendimentos nacionalistas governamentais mexicanos, Eisenstein construiu imagens e resgatou elementos nacionais, valorizando o folclore, o campo, o indígena, os símbolos geográficos, assim como fizeram os cineastas nacionais durante a Era de Ouro. Para possibilitar seu projeto, foram necessários nove meses de gravação e aproximadamente 70 mil metros de filme gravado, que seriam organizados em prólogo, epílogo e histórias nomeadas Sandunga, Maguey, Fiesta e Soldadera (TORRES, ESTREMERA, 1973).

Aurelio de los Reyes (2001) aponta diversos elementos importantes que contribuíram para o processo de construção e idealização de Que Viva México!, antes

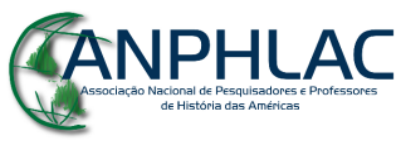

Revista Eletrônica da ANPHLAC, ISSN 1679-1061, №. 23, p. 146-173, Jul./Dez., 2017. http://revista.anphlac.org.br 
mesmo de o cineasta chegar em terras mexicanas. Politicamente, menciona a aproximação política do México com a União Soviética e a República de Weimar, tanto que o país manteve relações com a URSS após a Revolução de 1917 e permaneceu neutro durante a Primeira Guerra Mundial. Ainda, no ano de 1921, durante o governo de Álvaro Obregón, foi enviada uma delegação especial soviética ao México, e uma delegação mexicana de trabalhadores participou da Terceira Internacional na URSS.

Poucos anos depois, em 1923, o presidente eleito Plutarco Elias Calles visitou a Alemanha, fortalecendo laços culturais e comerciais com o país, enviando, inclusive, exemplares de livros para o Instituto Ibero-Americano da Biblioteca Pública de Berlim. A edição de Mexiko pelo fotógrafo Hugo Brehme e de publicações organizadas pelo jornalista alemão Alfons Goldschmidt, ilustradas com desenhos de Diego Rivera, fotografias de elementos culturais pré-colombianos, indígenas, resultam da aproximação dos países. Também, a revista alemã Arbeiter Illustrierte Zeitung, da qual foram encontradas matérias no arquivo pessoal de Eisenstein, publicou, na década de 1920, diversas matérias sobre o México. A revista Kölnische Illustrierte Zeitung, também publicou, em 1928, artigos sobre a rebelião cristera, ilustrada com fotografias de Enrique Diaz, que retrata os cadáveres dos cristeros enforcados nos postes de luz elétrica. Conforme observa De Los Reyes (2001), uma cópia da mesma fotografia foi utilizada por Grigory Alexandrov para apresentar sua versão de Que viva México!.

O contato com fotógrafos (Tina Modotti, Edward Weston, Anita Brenner) e com periódicos instigaram, segundo De Los Reyes (2001) e Tuñon (2002), o interesse do soviético em relação ao México. Diego Rivera já se tornara conhecido de Eisenstein por meio de Vladimir Maiakovsky, poeta e amigo. "De uma ou outra maneira, o mesmo gordo Diego, as fotografias de seus afrescos e seus coloridos relatos sobre o México incendiaram ainda mais minhas ganas de ir até lá e ver tudo com meus próprios olhos" (EISENSTEIN apud TUÑON, 2002, online).

No ano de 1930, após ter viajado para diversas cidades e ter, nos EUA, firmado contratos com a Paramount - os quais não se concretizaram, pois seus projetos e os interesses hollywoodianos não eram compatíveis (TUÑON, 2002) - Eisenstein rumou ao México, a fim de desenvolver um filme sobre o país. Antes da viagem, ainda nos Estados Unidos, procurou Upton Sinclair, com quem negociou sua realização. Segundo

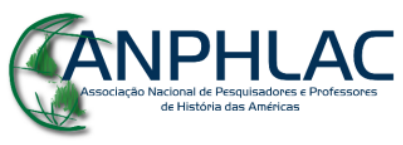

Revista Eletrônica da ANPHLAC, ISSN 1679-1061, №. 23, p. 146-173, Jul./Dez., 2017. http://revista.anphlac.org.br 
dados informados por Noble (2006), Eisenstein obteve um financiamento de aproximadamente US\$25.000 de Sinclair e sua esposa Mary Craig.

O contrato, segundo Tuñon (2002), feria algumas práticas primordiais para Eisenstein: dava a Sinclair o direito exclusivo aos direitos comerciais do filme, determinava a obrigatoriedade da edição ser realizada em Los Angeles e não necessariamente pelo diretor - o que era uma prática recorrente nos EUA, mas não para Eisenstein, cuja abordagem cinematográfica exige a união entre direção e montagem. Ainda, firmou-se a realização de um filme apolítico, pois tanto Sinclair quanto o governo mexicano temiam que o teor do filme ferisse as ideias de conciliação social do nacionalismo cultural. Por isso, foi necessário que o governo mexicano aprovasse o roteiro.

No dia 7 de dezembro de 1930, Eisenstein chegou ao México junto a Grigory Alexandrov e Eduard Tissé, respectivamente seu assistente e fotógrafo. Nos primeiros dias, sem um roteiro pronto para o filme, capturou imagens de festas em homenagem à Virgem de Guadalupe em Tacuba, visitou Azcapotzalco e a Villa de Guadalupe, adquiriu materiais sobre a aparição da Virgem, investigou sobre o Dia dos Mortos através da obra de Jose Guadalupe Posada e comprou diversos livros, como: uma versão em inglês e ilustrada por Jose Clemente Orozco do livro Los de Abajo, de Mariano Azuela; Las obras de José Guadalupe Posada de Frances Toor; Mexico, The Land of Unrest, de Henry Baerlein; Mexican Maze, de Carleton Beals; Mexico y Mexico and its Heritage de Ernest Grüening (DE LOS REYES, 2001).

Interessante notar que, ao mencionar seus projetos, em publicação realizada no periódico El Universal no dia 9 de dezembro de 1932, Eisenstein mostra como seu roteiro de viagem, para a elaboração fílmica, já estava estruturado mesmo poucos dias após sua chegada ao país, focando em regiões e aspectos folclóricos que representavam, interna e externamente, o México e o "típico" mexicano.

Durante um mês aproximadamente me dedicarei a estudar o ambiente mexicano, e depois procederei à manufatura do filme baseada no assunto local. Depois deste estudo decidirei se a obra a baseamos em um argumento determinado ou em uma exposição fiel do país, de seus costumes e de seu povo, documentando-me previamente em visitas que realizarei ao Distrito Federal e regiões imediatas, ao Istmo de Tehuantepec e a Yucatán, pois não omitirei por nenhum motivo as famosas ruínas de Chichén Itzá, e meu

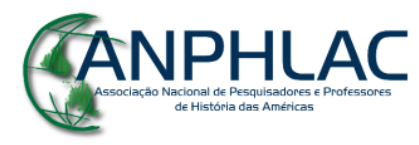

Revista Eletrônica da ANPHLAC, ISSN 1679-1061, №. 23, p. 146-173, Jul./Dez., 2017. http://revista.anphlac.org.br 
interesse pelo folclore local é enorme. (EISENSTEIN apud DE LOS REYES, 2001, p. 168)

Durante sua estadia no México, Eisenstein e sua equipe foram acompanhados de perto por Adolfo Best Maugard e Gabriel Fernández Ledesma, a trabalho da Secretaria de Educação, que tinham como objetivo garantir que não houvesse mistificações ou deturpações da imagem do México - como o cinema estadunidense fazia -, não fossem reproduzidos clichês negativos ou críticas e referências à desigualdade social presente no país (NOBLE, 2006). Interessante notar que o contexto político-cultural em que Eisenstein viajou para o México e registrou o país foi, conforme já exposto acima, um período de nacionalismo cultural, presença forte do governo nas relações sociais, bem como nas iniciativas culturais. Havia, por parte do Estado, a preocupação de evitar a construção de estereótipos pelos estrangeiros. Ao mesmo tempo, os estereótipos oficialmente consolidados, enfatizados e aceitos sobre o mexicano "típico" permeavam todo esse contexto, estendendo-se até o final dos anos 1940.

A influência de Eisenstein para a construção do estilo clássico do cinema mexicano - do qual as parcerias entre o diretor Emílio Fernández e o fotógrafo cinematográfico Gabriel Figueroa são as principais referências - é enfatizada por diferentes estudiosos do cinema e da cultura mexicana. Segundo Noble (2006), por um lado, ainda no ano de 1931, Eisenstein é evocado como um descobridor das imagens e das belezas mexicanas, o pioneiro entre cineastas mexicanos e estrangeiros a retratar tal riqueza. Para Adolfo Fernández Bustamante, ver o México através das lentes do soviético é ver o México real, suas belas paisagens e riqueza cultural.

Bustamante, no ano de 1932, escreveu:

[...] Eisenstein e os seus não fizeram uma cena que pudesse chamar-se internacional; tudo é absolutamente mexicano, [...] e, entretanto, não há nada de mau gosto, não há um só detalhe que resulte incômodo para nossa nacionalidade... maneja grupos, conjuntos que vão dando ideias mais claras das emoções, e esquecem o estilo yanqui dos heróis ridículos, sempre triunfadores graças a seu tipo atraente ou a sua maior ou menor perícia em jogar esse esporte canibalesco do "rugby" [...]. (BUSTAMANTE apud PÉREZ MONTFORT, 2015, p. 23, grifo nosso, aspas do autor)

O pintor Adolfo Best Maugard também se mostrou a favor das imagens do soviético, contrárias às deturpações construídas em Hollywood até então. Também, no

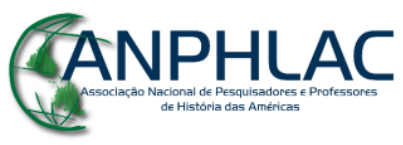

Revista Eletrônica da ANPHLAC, ISSN 1679-1061, №. 23, p. 146-173, Jul./Dez., 2017. http://revista.anphlac.org.br 
ano de 1932, afirmou que o cineasta soviético "[...] veio ao nosso país para, após o chamariz de nossas lendas, encontrar a verdade estética das maravilhas mexicanas, tanto desconhecidas no estrangeiro, quanto caluniadas [...]" (MAUGARD apud PÉREZ MONTFORT, 2015, p. 24). Por outro lado, Jorge Ayala Blanco, em crítica publicada no ano de 1968, acreditava que, naquele momento, o cinema mexicano "começa a libertarse do nefasto equívoco de herança eisensteiniana" (NOBLE, 2006, p. 173).

John Mraz (2009), por exemplo, acredita que, assim como Luis Buñuel, Hugo Brehme e Henri Cartier-Bresson, Eisenstein influenciou de forma marcante a construção da identidade nacional mexicana, o qual, junto a Edward Tisse, explorou as imagens pitorescas dos vulcões, cactos, nuvens e camponeses, construindo um imaginário sobre a cultura, história e costumes mexicanos que seriam referência para artistas mexicanos e estrangeiros.

Emilio García Riera (1969) vê clara influência entre o México de Eisenstein e o México imaginado pelos mexicanos, sendo a indústria cinematográfica nacional uma união entre os quadros eisensteinianos e a técnica hollywoodiana. O ponto levantado por Riera - a influência estadunidense no imaginário nacional mexicano - também se apresenta nas reflexões de Ricardo Pérez Montfort (2015), para quem é bastante claro que a imagem do México a nível internacional foi influenciada por Eisenstein e Tissé, e também pelos filmes sobre o México realizados em Hollywood. Noble (2006) enfatiza as complexas relações entre o visitante e o anfitrião, sendo as influências entre ambos partes de um processo intercultural - assim como o foram as trocas entre mexicanos e outros artistas estrangeiros.

O filme Redes, de Fred Zinnemann y Emilio Gómez Muriel, é considerado, por Tuñon (2002) e por diversos estudiosos do período, como uma das produções mexicanas mais influenciadas por Eisenstein, tanto nas imagens quanto no enredo, sendo um filme-manifesto, levantando ideais de justiça social e expondo conflitos éticos, ações pouco comuns no cinema mexicano e presença marcante no cinema de Eisenstein.

Além das relações de Eisenstein com artistas mexicanos já mencionados, Noble (2006) aponta a amizade do soviético com os pintores muralistas como tendo aquele a intensão de realizar um mural cinematográfico. A busca por levar os murais às telas de cinema é também compartilhada pelo diretor Emílio Fernández e pelo fotógrafo Gabriel

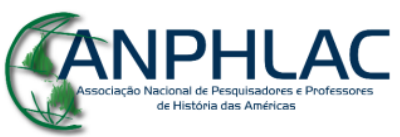

Revista Eletrônica da ANPHLAC, ISSN 1679-1061, №. 23, p. 146-173, Jul./Dez., 2017. http://revista.anphlac.org.br 
Figueroa, que se orgulha em ser o quarto muralista - ao lado de Rivera, Orozco e Siqueiros (VAZQUEZ MANTECÓN, 1996). Fernández, na visão de Tuñon (2002), mescla a influência do soviético e os padrões hollywoodianos, construindo uma imagem tanto nacionalista, quanto apreciada e premiada no exterior. Por sua vez, Eduard Tissé representa importante influência para Gabriel Figueroa - seus filtros, sua perspectiva, seus céus, suas nuvens, luzes e sombras.

Percebemos, através das discussões apresentadas, que a passagem de Eisenstein no México possibilitou a elaboração de um filme que, mesmo incompleto, levantou intensos debates sobre o mexicano, o típico, o nacional. Conforme os questionamentos que nortearam nossa análise, percebemos a força e a influência internacional no México dos anos 30 e 40 nos empreendimentos nacionalistas estatais e no processo de construção de um imaginário nacional. A ampla rede de contatos e trocas nos possibilita entender esta produção cinematográfica, bem como este período da história mexicana, não como um cinema nacionalista produtor de estereótipos duvidosos e simplistas, mas como um cinema transnacional, permeado de complexidade, no qual interagem aspectos econômicos, políticos, sociais, culturais, por meio de pontes construídas entre artistas que perpassam as fronteiras nacionais.

\section{Referências bibliográficas}

ALBANO, Sebastião Guilherme. A imaginação atrofiada: Indústrias do cinema no Brasil e na América Hispânica. Revista Elementa Comunicação e Cultura. Sorocaba, v. 1, n. 1, jan./jun., 2009.

ARROYO, Claudia; RAMEY, James; SCHUESSLER, Michael. Una coherencia imaginaria: reflexiones desde México sobre el concepto de cine nacional. In (Eds.). México imaginado: Nuevos enfoques sobre el cine (trans)nacional. México, D.F.: CONACULTA y Universidad Autónoma Metropolitana, 2011.

BAMBA, Mahomed. Os espaços de recepção transnacional dos filmes: propostas para uma abordagem semiopragmática. Crítica Cultural, Palhoça-SC, n. 2, v. 8, Jul./Dez. 2013.

BARBOSA, Carlos Alberto Sampaio. 20 de novembro de 1910: a Revolução Mexicana. São Paulo: Companhia Editora Nacional: Lazuli Editora, 2007.

BARTRA, Roger. The Mexican Office: The Splendors and Miseries of Culture. In: FERMAN, Claudia (Ed.). The Postmodern in Latin and Latino American Cultural

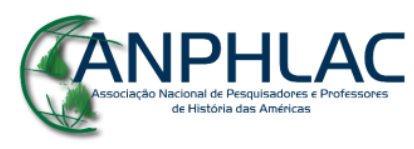

Revista Eletrônica da ANPHLAC, ISSN 1679-1061, №. 23, p. 146-173, Jul./Dez., 2017. http://revista.anphlac.org.br 
Narratives: Collected Essays and Interviews. New York, London: Garland Publishing, 1996.

BRAGANÇA, Maurício de. Metáforas à mesa: Bustillo Oro, Buñuel, Ripstein e o Melodrama familiar mexicano. In: AMANCIO, Tunico; TEDESCO, Marina Cavalcanti (Orgs.). Brasil - México: aproximações cinematográficas. Niterói: Editora da Universidade Federal Fluminense, 2011.

CAPELATO, Maria Helena Rolim. Modernismo latino-americano e construção de identidades através da pintura. Revista de História, n. 153, v. 2, 2005.

CASTRO, Francisco Peredo. Cine y propaganda para Latinoamerica: México y Estados Unidos en la encrucijada de los años cuarenta. México, D.F.: UNAM, Centro Coordinador y Difusor de Estudios Latinoamericanos, Centro de Investigaciones sobre América del Norte, 2004.

CORDERO REIMAN, Karen. La invención del arte popular y la construcción de la cultura visual moderna en México. In: ACEVEDO, Esther (Coord.). Hacia otra historia del arte en México: la fabricación del arte nacional a debate (1920-1950). México, D.F.: CONACULTA, 2002.

CUEVA, Alicia Azuela de la. Arte y poder: renacimiento artístico y revolución social. México, 1910-1945. Zamora, Michoacán: El Colegio de Michoacán: Fondo de Cultura Económica, 2005.

DE LOS REYES, Aurelio. El nacimiento de ¡Que viva México! de Serguei Eisenstein: conjeturas. Anales del Instituto de Investigaciones Estéticas, n. 78, 2001.

ESCOBAR, Juan Pablo Silva. La Época de Oro del cine mexicano: la colonización de un imaginário social. Culturales, v. VII, n. 13, enero-junio, 2011.

EZRA, E.; ROWDEN, T. (Orgs.). Transnational cinema: the film reader. New York: Routledge, 2006.

GARCÍA RIERA, Emilio. Historia documental del cine mexicano. Tomo 1, 1926/1940. México: Editorial ERA, 1969.

HIGGINS, Ceri. Gabriel Figueroa: Nuevas Perspectivas. México, D.F.: Dirección General de Publicaciones del CNCA, 2008.

MONTEIRO, José Carlos. Pirâmides de imagens: a invenção da Edad de Oro na historiografia do cinema mexicano. In: AMANCIO, Tunico; TEDESCO, Marina Cavalcanti. Brasil - México: aproximações cinematográficas. Niterói: Editora da Universidade Federal Fluminense, 2011.

MONSIVÁIS, Carlos. Notas sobre la cultura mexicana en el siglo XX. In: CENTRO DE ESTUDIOS HISTÓRICOS. Historia General de México, tomo 2. México, D.F.: El Colegio de México/ Editorial Harla, 1988.

MRAZ, John. Looking for Mexico. Modern Visual Culture and National Identity. London: Duke University Press, 2009.

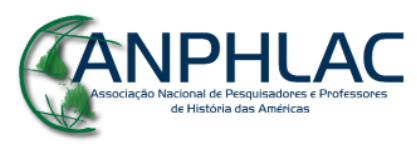

Revista Eletrônica da ANPHLAC, ISSN 1679-1061, №. 23, p. 146-173, Jul./Dez., 2017. http://revista.anphlac.org.br 
NOBLE, Andrea. Seeing through ¡Que viva México!: Eisenstein's Travels in Mexico. Journal of Iberian and Latin American Studies. v. 12, n. 2-3, August/December, 2006.

OROZ, Silvia. Melodrama: o cinema de lágrimas da América Latina. Rio de Janeiro: Rio Fundo Editora, 1992.

PÉREZ MELGOSA, Adrián. Cinema and Inter-American Relations: Tracking Transnational Affect. New York: Routledge, 2012.

PÉREZ MONTFORT, Ricardo. El pueblo y la cultura: del porfiriato a la Revolución. In: BÉJAR, Raúl; ROSALES, Héctor (Coords.). La identidad nacional mexicana como problema político y cultural. Nuevas miradas. Cuernavaca: UNAM, Centro Regional de Investigaciones Multidisciplinarias, 2005.

PÉREZ MONTFORT, Ricardo. Indigenismo, hispanismo y panamericanismo en la cultura popular mexicana de 1920 a 1940. In: BLANCARTE, Roberto (Coord.). Cultura e identidad nacional. México: FCE, CONACULTA, 2007.

PÉREZ MONTFORT, Ricardo. Nacionalismo y regionalismo en el cine Mexicano 1930-1960. Algunas reflexiones. Revista Chilena de Antropología Visual, Santiago, n. 25, julio, 2015.

SCHUMANN, Peter B. Historia del cine latinoamericano. Buenos Aires: Editorial Legasa, 1987.

TORRES, Augusto Martínez; ESTREMERA, Manuel Pérez. Nuevo Cine Latinoamericano. Barcelona: Editorial Anagrama, 1973.

TUÑON, Julia. Serguei Eisenstein y Emilio Fernández: constructores fílmicos de México. Los vínculos entre la mirada própria y ajena. Film Historia, v. XII, n. 3, 2002. Disponível em: http://www.publicacions.ub.edu/bibliotecaDigital/cinema/filmhistoria/2 002/eisenstein.htm\#topUP Acesso em: 18 de julho de 2017.

VALDELLÓS, Ana Sedeño; MUÑOZ, María Jesús Ruiz. Cine y globalización: hacia un concepto de cine transnacional. Tenerife, España: Actas - III Congreso Internacional Latina de Comunicación Social - III CILCS - Universidad de La Laguna, diciembre 2011.

VASSILIEVA, Julia. Sergei Eisenstein's ¡Que viva Mexico! through time: Historicizing value judgement. Continuum: Journal of Media \& Cultural Studies. v. 24, n. 5, October, 2010.

VÁZQUEZ MANTECÓN, Álvaro. Los tres grandes eran cuatro. In: Gabriel Figueroa y la pintura mexicana, México: Museo Carrillo Gil-INBA, 1996.

XAVIER, Ismail. $O$ discurso cinematográfico: a opacidade e a transparência. $3^{\text {a }}$ edição. São Paulo: Paz e Terra, 2005.

XAVIER, Ismail. O olhar e a cena: Melodrama, Hollywood, Cinema Novo, Nelson Rodrigues. São Paulo: Cosac \& Naify, 2003.

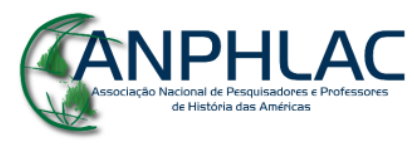

Revista Eletrônica da ANPHLAC, ISSN 1679-1061, №. 23, p. 146-173, Jul./Dez., 2017.

http://revista.anphlac.org.br 
¿QUE VIVA MÉXICO! Direção: Serguei M. Eisenstein. Fotografia: Eduard Tissé. Produção: Upton Sinclair, Mary Craig Sinclair, Kate Crane Gartz, S. Hillkowitz, Otto Kahn e Hunter S. Kimbrough. Roteiro: Sergei M. Eisenstein e Grigory Alexandrov. Edição: Sergei M. Eisenstein (parte do material original); Grigory Alexandrov e Esfir Toback (versão de 1977). Trilha sonora: Juan Aguilar y Francisco Camacho Veja. União Soviética; Estados Unidos; México, 1977 (90 min.), preto e branco. 